\title{
X-ray photoelectron spectroscopy study of the degradation of Pt/ITO electrocatalyst in an operating polymer electrolyte fuel cell
}

Guanxiong Wang ${ }^{\mathrm{a}}$, Kaustava Bhattacharyya ${ }^{\mathrm{b}}$, Javier Parrondo $^{\mathrm{a}}$ and Vijay Ramani ${ }^{\mathrm{a}^{*}}$

${ }^{a}$ Center for Electrochemical Science and Engineering, Department of Chemical and Biological

Engineering, Illinois Institute of Technology, 10 W. $33^{\text {rd }}$ St., Chicago, IL 60616

*Corresponding author’s e-mail: ramani@iit.edu

${ }^{\mathrm{b}}$ Chemistry Division, Bhabha Atomic Research Center, Mumbai-400085, India 


\begin{abstract}
We investigate the performance and stability of a platinum $(\mathrm{Pt})$ supported on indium tin oxide (ITO) electrocatalyst. ITO was synthesized using the co-precipitation method and uniform particles with a B.E.T. surface area larger than $40 \mathrm{~m}^{2} / \mathrm{g}$ were obtained. Pt was dispersed onto the ITO by colloidal deposition followed by reduction with formaldehyde. Previous rotating disk electrode (RDE) work has shown that Pt/ITO possesses high activity and stability for the oxygen reduction reaction (ORR). However, this catalyst exhibited very poor performance and stability in an operating polymer electrolyte fuel cell (PEFC) membrane electrode assembly (MEA). For $\mathrm{H}_{2} / \mathrm{O}_{2}$ PEFC operation at $80{ }^{\circ} \mathrm{C}$ and $75 \%$ relative humidity $(\mathrm{RH})$, the current density obtained at $0.55 \mathrm{~V}$ was only $90 \mathrm{~mA} / \mathrm{cm}^{2}$, and the maximum current density was only $150-160 \mathrm{~mA} / \mathrm{cm}^{2}$, when $\mathrm{Pt} / \mathrm{ITO}$ was used at the cathode, whereas a limiting current density of $3900 \mathrm{~mA} / \mathrm{cm}^{2}$ was readily obtained using a benchmark $\mathrm{Pt} / \mathrm{C}$ catalyst under identical conditions. The low performance with Pt/ITO was primarily due to the high overall cell resistance of the MEA (> $\left.400 \mathrm{mOhm}-\mathrm{cm}^{2}\right)$. X-ray photoelectron spectroscopy (XPS) was employed to investigate the degradation of the $\mathrm{Pt} / \mathrm{ITO}$ catalyst in the PEFC electrode during operation. The deconvolution of the indium $3 \mathrm{~d}$ XPS peak revealed the presence of two peaks: the first was assigned to indium oxide in ITO (at $445.6 \mathrm{eV}$ ), while the second was assigned to indium hydroxide (at $446.6 \mathrm{eV}$ ). We observed an increase in surface hydroxide concentration (compared to pristine Pt/ITO) after the Pt/ITO catalyst was used either at the cathode or anode of an operating PEFC. We postulate that the surface hydroxides form a passivating layer that increases the electrode resistance and undermines PEFC performance.
\end{abstract}




\section{Introduction}

Polymer electrolyte fuel cells (PEFCs) are excellent energy conversion devices that convert chemical energy of fuels such as hydrogen directly to electrical energy with high power density, high efficiency, and zero emissions. Today, fuel cells have applications primarily in three broad areas: portable power generation, stationary power generation, and as power sources in transportation applications. There exist several challenges that hinder the commercialization of fuel cells, such as the high cost of components (especially the high cost of carbon-supported-platinum-based (Pt/C) electrocatalysts) and insufficient durability/reliability of these catalysts. Carbon support corrosion has been identified as the major issue contributing to $\mathrm{Pt} / \mathrm{C}$ electrocatalyst failure. When the carbon support is electrochemically oxidized during fuel cell operation, the lifetime of the PEFC is greatly reduced (Kinoshita and Bett, 1973; Kangasniemi et al., 2004; Roen et al., 2004; Takeuchi and Fuller, 2008; Antolini and Gonzalez, 2009). This process can be expressed by the following reaction:

$\mathrm{C}+2 \mathrm{H}_{2} \mathrm{O} \rightarrow \mathrm{CO}_{2}+4 \mathrm{H}^{+}+4 \mathrm{e}^{-} \mathrm{E}=0.207 \mathrm{~V}$ vs. reversible hydrogen electrode (RHE)

Though this reaction is very sluggish under normal fuel cell cathode operating potentials $(0.55-0.95 \mathrm{~V})$, it can be accelerated tremendously during transient potential spikes that occur during fuel cell start-up and shut down, and in the event of local fuel starvation (at the anode), leading to carbon corrosion at the cathode/anode (Reiser et al., 2005; Meyers and Darling, 2006; Patterson and Darling, 2006; Tang et al., 2006; Maass et al., 2008; Shen et al., 2009; Schneider and von Dahlen, 2011). Other factors, such as Pt dissolution, sintering, and agglomeration, also contribute to the catalyst degradation process.(Mahlon S. Wilson, 1993; Darling and Meyers, 2003; Wang et al., 2006; Shao et al., 2007; Yu and Ye, 2007)

Although carbon supports are outstanding in many respects due to their high B.E.T. surface area 
and excellent electrical conductivity, the corrosion caused by electrochemical oxidation in operating PEFCs has been identified to be a major downside in terms of carbon-supported catalyst durability and reliability. Moreover, the irreversible loss of the carbon support causes the detachment of the platinum nano particles from the support and contributes to Pt nano particle agglomeration. The detached Pt nano particles also became electrically isolated, leading to lower Pt utilization, resulting in an evident degradation of fuel cell performance (Mahlon S. Wilson, 1993; Ferreira et al., 2005; Borup et al., 2007; Zhang et al., 2007).

It is therefore expedient and judicious to investigate stable alternative supports to replace carbon in an effort to improve PEM fuel cell durability and performance. Various non-carbon catalyst support alternatives have been investigated to date, including a variety of metal oxides (Sharma and Pollet, 2012), metal carbides (Shanmugam et al., 2005; Chhina et al., 2007; Liu et al., 2013), metal nitrides (Avasarala and Haldar, 2010), and conducting polymers and other hybrid materials (Wang et al., 2011; Sharma and Pollet, 2012).Since the durability of the catalyst support at high potentials (1.0-1.5V vs. RHE) remains a key requirement in developing a stable catalyst support, some metal oxides, more specifically conducting mixed metal oxides, are of high interest. Various metal oxides/mixed metal oxides have been investigated as substitutes for carbon materials, such as tin-doped indium oxide (ITO) (Chhina et al., 2006; Liu and Mustain, 2013), $\mathrm{SnO}_{2}$ (Santos et al., 2005; Hagemeyer et al., 2007), $\mathrm{TiO}_{2}$ (Chen et al., 2002; Haas et al., 2008), doped $\mathrm{TiO}_{2}$ (with Mo, Ta, Nb, Ru as dopant) (Huang et al., 2010; Ho et al., 2011; Thanh Ho et al., 2011; Kumar and Ramani, 2014), $\mathrm{SiO}_{2}$ (Zhu et al., 2006; Seger et al., 2008), $\mathrm{WO}_{\mathrm{x}}$ (Rajeswari et al., 2007; Cui et al., 2008; Liu et al., 2012), $\mathrm{RuO}_{2}-\mathrm{TiO}_{2}$ (Lo et al., 2013; Parrondo et al., 2014) and $\mathrm{RuO}_{2}-\mathrm{SiO}_{2}$ (Lo and Ramani, 2012; Kumar and Ramani, 2013).

ITO is a wide band gap semiconductor (band gap 3.7eV) and has been used successfully in many applications, including optoelectronic devices (Exarhos and Zhou, 2007; Granqvist, 2007; Song et al., 2010), photovoltaic cells (Bellingham et al., 1991), electrochromic devices 
(Corradini et al., 1990), and liquid crystal displays (Kazunari et al., 1994). ITO is a transparent conducting oxide, with high conductivity that has been used as a support for Pt electrocatalysts in several prior published reports (Chhina et al., 2006; Liu and Mustain, 2013). Rotating disk electrode (RDE) experiments have shown that Pt supported on ITO has good electrochemical stability and high oxygen reduction reaction (ORR) activity (Chhina et al., 2006; Liu and Mustain, 2013). Chhina et al. reported that the hydrogen desorption peaks in the cyclic voltammograms (CVs) were retained after 100 potential cycles from 0.6 to $1.8 \mathrm{~V}$ (vs. SHE) in $\mathrm{Pt}$ catalyzed ITO, where as they almost disappeared in a Pt/C catalyst (Johnson Matthey, 40\% Pt, HiSPEC 4000) (Chhina et al., 2006). Liu et al. reported an extremely high mass activity for Pt/ ITO electrocatalyst via RDE studies $(621 \pm 31 \mathrm{~mA} / \mathrm{mgPt}$ at $0.9 \mathrm{~V}$ vs RHE). The enhanced ORR activity was attributed to the overwhelming proportion of $\mathrm{Pt}$ (111) facets in the Pt nanoparticles (Liu and Mustain, 2013). The ITO support and Pt/ITO have demonstrated exceptional electrochemical stability in our own RDE tests (confirming the results of Chinna et al. and Liu et $a l$.). Despite these encouraging reports based on RDE studies, there are minimal reports on the performance and durability of Pt/ITO in an operating PEFC. A more comprehensive investigation of Pt/ITO, especially with regard to performance and durability in membrane electrode assemblies (MEAs) has to be completed before arriving at a verdict on the efficacy of ITO as a stable support for Pt electrocatalysts.

The objective of this work was to systematically investigate the performance and stability of Pt/ITO in an MEA during regular fuel cell operation. High surface area ITO was synthesized using a co-precipitation method, in order to obtain uniform particles with large B.E.T. surface areas $\left(>40 \mathrm{~m}^{2} / \mathrm{g}\right)$. Colloidal deposition was used to attach Pt onto the ITO support. MEAs were prepared by painting the electrocatalyst layer onto a gas diffusion layer and sandwiching an electrolyte membrane between two such electrodes. The MEAs were evaluated under typical operating conditions. Structural changes in Pt/ITO were evaluated (post MEA testing) using X-ray photoelectron spectroscopy (XPS) to unearth the support degradation mechanism. 


\section{Experimental Methods}

\subsection{Synthesis of ITO electrocatalyst support}

$2 \mathrm{~g}$ of indium nitrate was dissolved in $200 \mathrm{~mL}$ deionized water. Once it was completely dissolved, $78 \mu \mathrm{L}$ of tin tetrachloride was added to the solution. A stock solution $(0.5 \mathrm{~mol} / \mathrm{L})$ of hexamethylenetetramine (HMT) in deionized water was then added in drop wise under stirring. HMT hydrolyzed slowly to yield ammonia and formaldehyde, raising the $\mathrm{pH}$ of the solution gradually and homogeneously. The solution was stirred overnight (at room temperature) to allow complete precipitation of the hydroxides. The precipitate was recovered by centrifugation(at $5,000 \mathrm{rpm}$ ), washed three times with deionized water and isopropanol, dried in a conventional oven at $60{ }^{\circ} \mathrm{C}$, ground into powder and annealed at $820{ }^{\circ} \mathrm{C}$ for 2.5 hours. The ITO was synthesized with an $\mathrm{In}_{2} \mathrm{O}_{3}$ to $\mathrm{SnO}_{2}$ weight ratio of 9:1.

\subsection{Deposition of platinum nanoparticles onto the ITO support}

$0.14 \mathrm{~g}$ of ITO was dispersed in $150 \mathrm{~mL}$ of deionized water. The $\mathrm{pH}$ adjusted to 7 by adding $\mathrm{NaHCO}_{3}$ solution, and the suspension was alternately stirred and sonicated for 2 hours to improve the dispersion and wettability of the support. $0.25 \mathrm{~g}$ of $\mathrm{H}_{2} \mathrm{PtCl}_{6}$ was dissolved in $15 \mathrm{~mL}$ of DI water and added dropwise to the ITO suspension. Subsequently, the mixture was alternately stirred and sonicated for another 2 hours to allow the precursor to adsorb onto the support surface. $195 \mu \mathrm{L}$ of formaldehyde (37 wt $\%$, reducing agent) was dissolved in $1.95 \mathrm{~mL}$ of DI water and added dropwise to the suspension containing the catalyst support and the Pt precursor. The mixture was stirred overnight at $80{ }^{\circ} \mathrm{C}$ to allow the complete reduction of the Pt precursor. The solid material comprising the Pt nanoparticles deposited onto the ITO support was recovered by filtration, washed with DI water, and dried in an oven at $60^{\circ} \mathrm{C}$. The catalyst was heated for 12 hours at $120^{\circ} \mathrm{C}$ in air. The nominal Pt loading in Pt/ITO was 40\%wt (verified by both XRD and 
EDX techniques).

$\underline{\text { 2.3.Membrane electrode assembly (MEA) fabrication and PEM fuel cell testing }}$

Catalyst ink preparation. 0.3 grams of 46\%Pt/C (Tanaka K.K, Japan; TEC10E50E) was wetted with a few drops of DI water. $6 \mathrm{~mL}$ of methanol was added to the wet catalyst, and the suspension was stirred for 5 minutes. 2.57 grams of Nafion ${ }^{\circledR}$ solution (5\%wt; Sigma Aldrich) was added, and the mixture was sonicated for 15 minutes before use. The amount of Nafion ${ }^{\circledR}$ ionomer added was calibrated to yield an ionomer to support (I:S) ratio of 0.8 grams/grams (corresponding to $30 \mathrm{wt} \%$ of ionomer in the electrode). A similar procedure was employed to prepare the ink with $40 \% \mathrm{Pt} / \mathrm{ITO}$. The optimum amount of $\mathrm{Nafion}^{\circledR}{ }^{\circledR}$ binder for a Pt/ITO electrode was lower than that for $\mathrm{Pt} / \mathrm{C}$, because: 1) the B.E.T. surface area of the ITO support was considerable lower than for the carbon support, and 2) the density of ITO was much higher than that of carbon. The I:S ratio employed for Pt/ITO electrodes was 0.4 grams/grams (corresponding to $20 \mathrm{wt} \%$ of ionomer loading in the electrode).

Preparation of the Gas Diffusion Electrodes $(G D E)$. The catalyst ink (Pt/C or Pt/ITO) was sprayed onto a carbon paper gas diffusion electrode (GDL; 25BCH from SGL Carbon) with the aid of an airbrush. Nitrogen (at 10 psig) was used as the carrier gas to spray the catalyst onto the gas diffusion layer. While spraying, we followed a set pattern to ensure uniform distribution of the catalyst on the GDL surface.

MEA preparation and fuel cell testing. Three types of MEAs were prepared and tested to evaluate catalyst stability and performance: 1) an MEA with Pt/ITO at the cathode and Pt/C at the anode; 2) an MEA with Pt/C at the cathode and Pt/ITO at the anode; and 3) an MEA with $\mathrm{Pt} / \mathrm{C}$ at both the cathode and anode (benchmark). The MEAs, each with an active surface area of $5 \mathrm{~cm}^{2}$ were prepared using Nafion ${ }^{\circledR} 211$ membrane separators and were assembled in the fuel cell 
hardware (sourced from Fuel Cell Technologies, Inc.) by placing the appropriate gas diffusion electrodes on each side of the membrane. Pt loadings of $0.4 \mathrm{mg}_{\mathrm{Pt}} / \mathrm{cm}^{2}$ in the cathode and $0.2 \mathrm{mg}_{\mathrm{Pt}} / \mathrm{cm}^{2}$ in the anode were employed (when using Pt/ITO in the anode, the loading was 0.4 $\mathrm{mg}_{\mathrm{Pt}} / \mathrm{cm}^{2}$ ). The MEA was assembled using two gaskets (Teflon ${ }^{\circledR}$ reinforced with fiberglass) with a thickness of 0.007 inches each (resulting in a pinch of approximately 0.0025 inches). A torque of $25 \mathrm{lb}_{\mathrm{F}} \cdot$ in was used uniformly across the hardware to complete the assembly.

Linear sweep voltammetry (LSV) was performed before acquiring any fuel cell polarization curves to ensure that there was no electrical shorting or excessive crossover. Cyclic voltammetry (CV) was then performed to estimate the electrochemically active surface area (ECSA) of the Pt in the cathode electrocatalyst. LSV was performed at a scan rate of $4 \mathrm{mV} / \mathrm{s}$ in the potential range 0.1 to $0.5 \mathrm{~V}$. CV was performed at a scan rate of $20 \mathrm{mV} / \mathrm{second}$ in the potential range $0.06 \mathrm{~V}$ to $1.0 \mathrm{~V}$. Both experiments were performed while passing $0.2 \mathrm{~L} /$ minute of hydrogen through the fuel cell anode, and $0.2 \mathrm{~L} /$ minute of nitrogen through the fuel cell cathode (working electrode). The fuel cell anode was used as pseudo-reference electrode in each case.

Fuel cell polarization curves were recorded after conditioning the MEA by holding the cell voltage at $0.55 \mathrm{~V}$ for 20 minutes. This conditioning step was performed to ensure steady state operation. The fuel cells tests were performed at $80^{\circ} \mathrm{C}$ and $75 \%$ relative humidity of the inlet gases (the temperature of the humidifiers was set at $73^{\circ} \mathrm{C}$ ). The current was then scanned from zero at the open circuit voltage $(\mathrm{OCV})$ to a value where the cell voltage dropped below $0.55 \mathrm{~V}$, with each current point held for 2 minutes. Then, the cell voltage was scanned from $0.55 \mathrm{~V}$ to 0.1 $\mathrm{V}$ using steps of $0.05 \mathrm{~V}$, holding at each voltage for 5 minutes. Polarization curves were acquired using hydrogen as the fuel and oxygen, air, Helox (21\% oxygen balance helium) and $4 \%$ oxygen (balance nitrogen) as oxidants. LSV and CV were performed again at the end of the polarization experiments to verify the condition of the MEA and to confirm that there was no crossover or shorting induced during the testing process. 


\subsection{X-ray photoelectron spectroscopy}

X-ray photoelectron spectroscopy (XPS) experiments were performed to analyze the electronic environment of the catalyst metals and metal oxide supports. The measurements were performed on a SPECS instrument with a PHOBIOS 100/150 delay line detector (DLD) with 385W -Power, $13.85 \mathrm{kV}$ and $175.6 \mathrm{nA}$ (sample current). An Al Ka (1486.6eV) dual anode was used as the X-ray source. The XPS measurements were obtained with a pass energy of $50 \mathrm{eV}$. The C-1s peak $(284.5 \mathrm{eV})$ was used as an internal reference to calibrate the absolute binding energy. The peaks deconvoluted and quantified using the CASA software where the baseline was executed using a Shirley background function.

\section{Results and discussion}

\subsection{MEA performance using Pt/ITO}

The $\mathrm{H}_{2} / \mathrm{O}_{2}$ fuel cell polarization curves for both types of Pt/ITO MEAs, as well as for the benchmark Pt/C MEA are shown in Figure S1-S4. The performance obtained with the MEA containing Pt/ITO at the cathode was very low, with a current density of $90 \mathrm{~mA} / \mathrm{cm}^{2}$ at $0.55 \mathrm{~V}$. The maximum current density obtained with this MEA in $\mathrm{H}_{2} / \mathrm{O}_{2}$ mode was $150-160 \mathrm{~mA} / \mathrm{cm}^{2}$. In contrast, a limiting current density of $3900 \mathrm{~mA} / \mathrm{cm}^{2}$ was readily obtained in $\mathrm{H}_{2} / \mathrm{O}_{2}$ mode with the benchmark MEA prepared with $\mathrm{Pt} / \mathrm{C}$ on both electrodes (Note that this benchmark MEA was prepared with the same Pt loading at each electrode and was assembled and tested using the same protocol). The low fuel cell performance obtained on the Pt/ITO-based MEA was a consequence of the high cell resistance (larger than $400 \mathrm{mOhm}-\mathrm{cm}^{2}$ ) and the low activity of the Pt in the Pt/ITO catalyst layer. Given the very low current densities, the gas-phase mass transport resistance should be quite low and the polarization curves obtained with Helox and air should be very close to one another. However, the performance obtained with air as oxidant was 
considerably lower than that obtained in the prior run with Helox (see Figure S1), which suggested that the Pt/ITO catalyst at the cathode was rapidly deteriorating even during the course of the experiment, i.e. over the course of a couple of hours. The fuel cell performance kept degrading over time and it did not recover when going back from air to Helox (Figure S7.)

The cell resistance evolution with time during the conditioning stage is shown in Figure $\mathbf{S 5}$ and the comparison of initial and final (measured at the end of the tests, after all the polarization curves with the all oxidants were recorded) fuel cell polarization curves and cell resistances for $\mathrm{Pt} / \mathrm{ITO}$ under $\mathrm{H}_{2} / \mathrm{O}_{2}$ is shown in Figure S6. From these figures, it is evident that the cell resistance kept increasing during the entire time the fuel cell was under operation. No such deterioration was observed in the benchmark MEA.

The poor performance was not limited to the MEA with Pt/ITO at the cathode. The MEA variant with Pt/ITO at the anode performed only marginally better than the MEA prepared with Pt/ITO at the cathode (See Figure S2); the current density (when operated in $\mathrm{H}_{2} / \mathrm{O}_{2}$ mode) at $0.55 \mathrm{~V}$ was $140 \mathrm{~mA} / \mathrm{cm}^{2}$-still very poor. The cell resistance was again larger than $400 \mathrm{mOhm}-\mathrm{cm}^{2}$.

We have conducted impedance spectroscopy (EIS) experiments for the MEA (Pt/ITO in the cathode and $\mathrm{Pt} / \mathrm{C}$ in the anode) before and after fuel cell operation. The details of the experiment can be found in the ESI (pages 9-10). The results showed a clear increase in the high frequency resistance (HFR) after the MEA was operated with $\mathrm{H}_{2} / \mathrm{O}_{2}$. An increase in the extension of the 45 degrees branch was also observed at high frequencies, (this is a clear indication of an increase in electrode resistance). (Lefebvre, 1999; Makharia et al., 2005; Liu et al., 2007) The EIS spectra (shown in Figure S8b) were fit to a model containing a distributed element (the equivalent circuit is schematically shown in Figure S8a). Additional details of the model can be found in the ESI. Initially (before the MEA was run in the fuel cell), the membrane resistance was 120 mOhm- $\mathrm{cm}^{2}$, and the electrode resistance was $345 \mathrm{mOhm}-\mathrm{cm}^{2}$. After the PEFC was run with 
$\mathrm{H}_{2} / \mathrm{O}_{2}$, the membrane resistance increased to $360 \mathrm{mOhm}-\mathrm{cm}^{2}$, and the electrode resistance to nearly $1400 \mathrm{mOhm}-\mathrm{cm}^{2}$. These trends were in agreement with the cell resistance obtained during fuel cell operation, and shown before. The increase in the electrode resistance supports our hypothesis that there a passivating layer formed on the surface of the electrodes. The enhancement in membrane resistance was attributed to a combination of indium ion ingress into the membrane and to enhanced contact resistances.

The performance with air was poorer than that the performance with Helox acquired in the next run, suggesting ongoing Pt/ITO degradation during the course of operation. To independently confirm ongoing degradation process for both types of MEAs containing Pt/ITO, we compared the initial $\mathrm{H}_{2} / \mathrm{O}_{2}$ performance obtained with a second $\mathrm{H}_{2} / \mathrm{O}_{2}$ run performed after 20 minutes of conditioning at $0.55 \mathrm{~V}$. These polarization curves are shown in Figure 1. A clear drop in performance was seen for both MEAs.

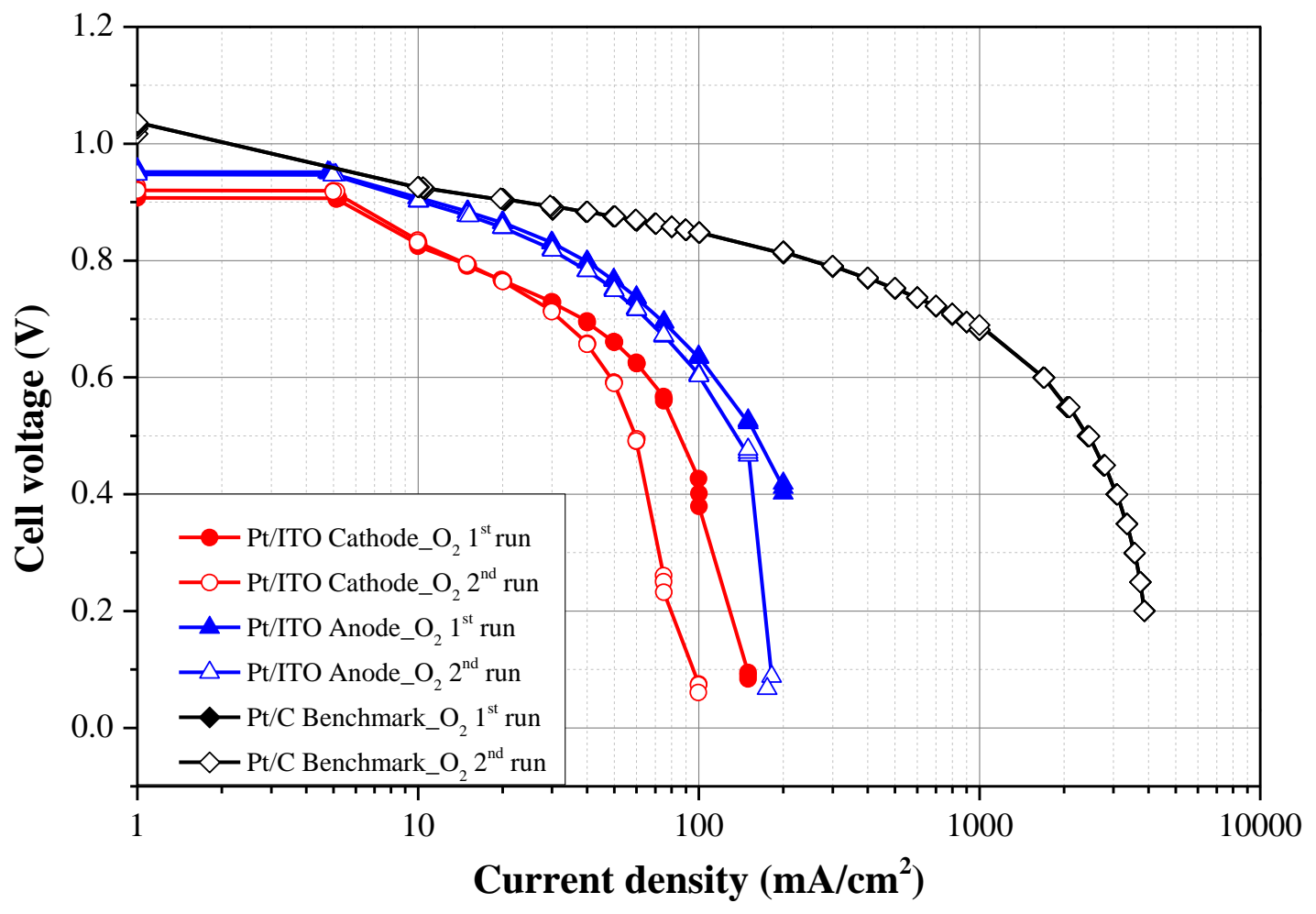


Figure 1. Degradation of fuel cell performance in MEAs containing Pt/ITO electrocatalysts at the anode or cathode after continuous operation at $0.55 \mathrm{~V}$ for 20 minutes.

Next, we investigated the trend in the electrochemically active surface area (ECSA) of the Pt/ITO electrocatalyst upon MEA operation. An ECSA of $21 \mathrm{~m}^{2} / \mathrm{g}$ Pt was observed at the beginning of the experiment (this value was in agreement with half-cell results), but decreased considerably after operation in the fuel cell under load, to the point where no discernable ECSA measurement could be made (see Figure 2). The hydrogen desorption peaks, clearly visible at the beginning, almost disappeared after operation in the fuel cell. The double layer capacitance was considerably lower after fuel cell testing, which suggested the corrosion of (or lack of access to) the catalyst support.

The discrepancy between the trends seen between RDE results (where Pt/ITO functions well) and MEAs results (where a significant drop in performance is seen) can be explained as follows: The catalyst layer in the RDE studies was very thin (less than $0.1 \square \mathrm{m}$ ), to minimize the mass transport resistance. This was partly accomplished by low catalyst loadings, and partly by very low ionomer binder loadings (the electrolyte was adequate to provide the requisite ion transport). The catalyst layer had very good contact with the glassy carbon and showed very low resistance (total cell resistance of approximately $6 \mathrm{Ohm}-\mathrm{cm}^{2}$. The Pt nanoparticles in the layer are very conductive and the catalyst layer was anchored by a very small amount of Nafion ${ }^{\circledR}$ binder (to minimize transport resistances). Thus, even with the electron conductivity changes in the support, the Pt nanoparticles would still function as electron conductors and allow the reaction to proceed. The ITO support degradation therefore did not affect the performance of the catalyst much in the RDE environment. In contrast, in the MEA environment, the much thicker electrodes and the much higher ionomer fraction precluded Pt from serving as an electron conductor efficiently, leading to a huge resistance once the support degraded and lost its conductivity. 
Based on these results, we postulate that catalyst support (ITO) degradation under MEA operating conditions was the primary contributor to poor MEA performance. Indium oxide can partially dissolve at low $\mathrm{pH}$ and high electrode potentials (Pourbaix, 1974). We posit that under the appropriate circumstances, the dissolved indium can re-precipitate on the surface of the electrode forming an indium hydroxide passivating layer that increases electrical resistance. These passivating layers not only result in large ohmic losses and in an ineffective support, but also in "disconnection" of the Pt nanoparticles from the electrode, reducing the effective $\mathrm{Pt}$ electrochemically active surface area.

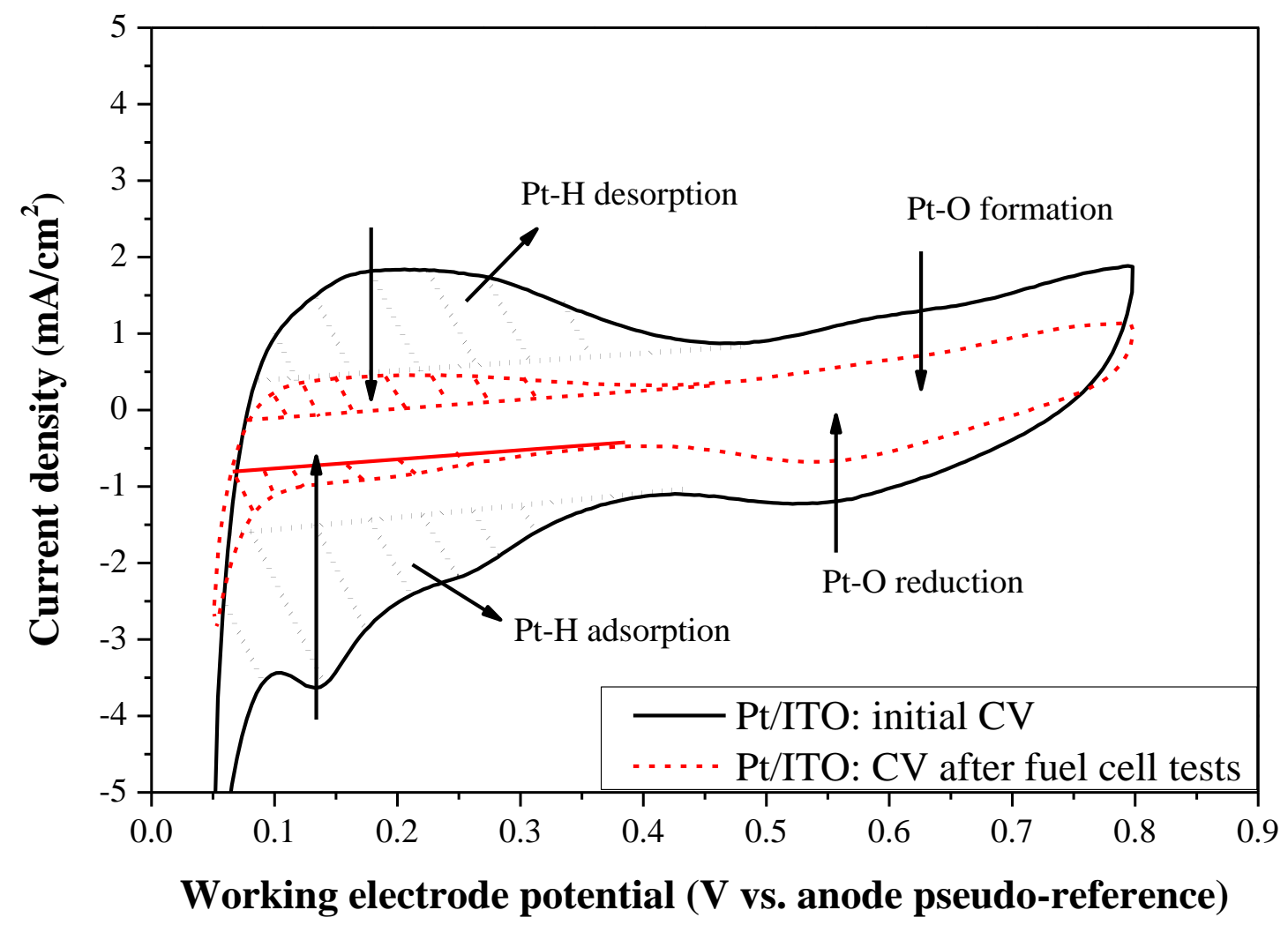

Figure 2. $\mathrm{CV}$ s for an MEA with $40 \% \mathrm{Pt} / \mathrm{ITO}$ at the cathode and $46 \% \mathrm{Pt} / \mathrm{C}$ at the anode, before and after testing in a fuel cell. 
3.2. Investigation of $\mathrm{Pt} / \mathrm{ITO}$ degradation during PEM fuel cell operation by using X-ray photoelectron spectroscopy (XPS)

To verify our hypothesis and to obtain a deeper understanding of the precise ITO degradation mechanism in the MEA, we performed XPS on the Pt/ITO electrocatalysts to examine the changes in electrocatalyst composition during fuel cell operation. The XPS measurements were performed on pristine Pt/ITO (before fuel cell testing) and post-test on Pt/ITO samples extracted from the MEA anode and cathode (for the first two types of MEA tested) after fuel cell operation. XPS was also performed on the benchmark Pt/C electrocatalyst.

Table 1 shows the relative percentage of the different elements present on the surface of the various electrodes. XPS measures the kinetic energy and counts the electrons that escape from the top 0-10 nm thick layer of the material (electrons ejected by the X-rays deeper in the material are absorbed by the material before they escape), and hence can only measure surface concentrations. XPS will not reveal any information about the bulk composition. The percentage of Pt was observed to be slightly lower in the Pt/C electrodes after operation in a fuel cell, when compared to the control Pt/C sample. This was attributed to surface Pt dissolution and migration into the electrolyte. In the case of Pt/ITO electrocatalyst, we observed a slight increase in the Pt surface concentration after MEA operation. The increase in Pt surface concentration provided spectroscopic evidence of loss of components such as In and/or Sn. Though the ITO crystals have shown excellent bulk chemical stability in acid and alkaline media, previous XPS studies on ITO have shown that the surface composition of ITO changes appreciably at high electrode potentials (Kohnke, 1962; Saadeddin et al., 2007; Zhao et al., 2015).

Table 1. XPS analysis of the surface of the electrocatalysts.

\begin{tabular}{|c|c|c|c|c|c|}
\hline Catalyst & $\begin{array}{l}\text { Electrode } \\
\text { being tested }\end{array}$ & Remarks & $\begin{array}{l}\text { Element } \\
\text { and orbital }\end{array}$ & $\begin{array}{l}\text { Binding } \\
\text { energy }(\mathrm{eV})\end{array}$ & $\begin{array}{l}\text { Atomic } \\
\text { percentage }(\%)\end{array}$ \\
\hline \multirow{4}{*}{$40 \% \mathrm{Pt} / \mathrm{ITO}$} & \multirow{4}{*}{---- } & \multirow{4}{*}{$\begin{array}{l}\text { Control (before } \\
\text { testing in MEA) }\end{array}$} & Pt-4d & 314.5 & 7.5 \\
\hline & & & Sn-3d & 486.5 & 4.1 \\
\hline & & & $\mathrm{O}-1 \mathrm{~s}$ & 530.5 & 73.4 \\
\hline & & & In-3d & 444.5 & 14.8 \\
\hline
\end{tabular}




\begin{tabular}{|c|c|c|c|c|c|}
\hline \multirow{4}{*}{$40 \% \mathrm{Pt} / \mathrm{ITO}$} & \multirow{4}{*}{ Anode } & \multirow{4}{*}{$\begin{array}{l}\text { After fuel cell } \\
\text { testing }\end{array}$} & Pt-4d & 315.1 & 12.0 \\
\hline & & & Sn-3d & 486.5 & 3.7 \\
\hline & & & O-1s & 530.5 & 70.3 \\
\hline & & & In-3d & 444.5 & 14.0 \\
\hline \multirow{4}{*}{$40 \% \mathrm{Pt} / \mathrm{ITO}$} & \multirow{4}{*}{ Cathode } & \multirow{4}{*}{$\begin{array}{l}\text { After fuel cell } \\
\text { testing }\end{array}$} & Pt-4d & 315.1 & 14.5 \\
\hline & & & Sn-3d & 486.5 & 4.5 \\
\hline & & & $\mathrm{O}-1 \mathrm{~s}$ & 530.5 & 64.7 \\
\hline & & & In-3d & 445.1 & 16.3 \\
\hline \multirow[t]{2}{*}{$46 \% \mathrm{Pt} / \mathrm{C}$} & \multirow[t]{2}{*}{--} & \multirow[t]{2}{*}{ Control } & Pt-4d & 315.5 & 3.4 \\
\hline & & & $\mathrm{C}-1 \mathrm{~s}$ & 284.5 & 96.6 \\
\hline \multirow[t]{2}{*}{$46 \% \mathrm{Pt} / \mathrm{C}$} & \multirow[t]{2}{*}{ Anode } & \multirow{2}{*}{$\begin{array}{l}\text { After fuel cell } \\
\text { testing }\end{array}$} & Pt-4d & 315.5 & 2.5 \\
\hline & & & $\mathrm{C}-1 \mathrm{~s}$ & 284.5 & 97.5 \\
\hline \multirow[t]{2}{*}{$46 \% \mathrm{Pt} / \mathrm{C}$} & \multirow{2}{*}{ Cathode } & \multirow{2}{*}{$\begin{array}{l}\text { After fuel cell } \\
\text { testing }\end{array}$} & Pt-4d & 315.5 & 2.9 \\
\hline & & & $\mathrm{C}-1 \mathrm{~s}$ & 284.5 & 97.1 \\
\hline
\end{tabular}




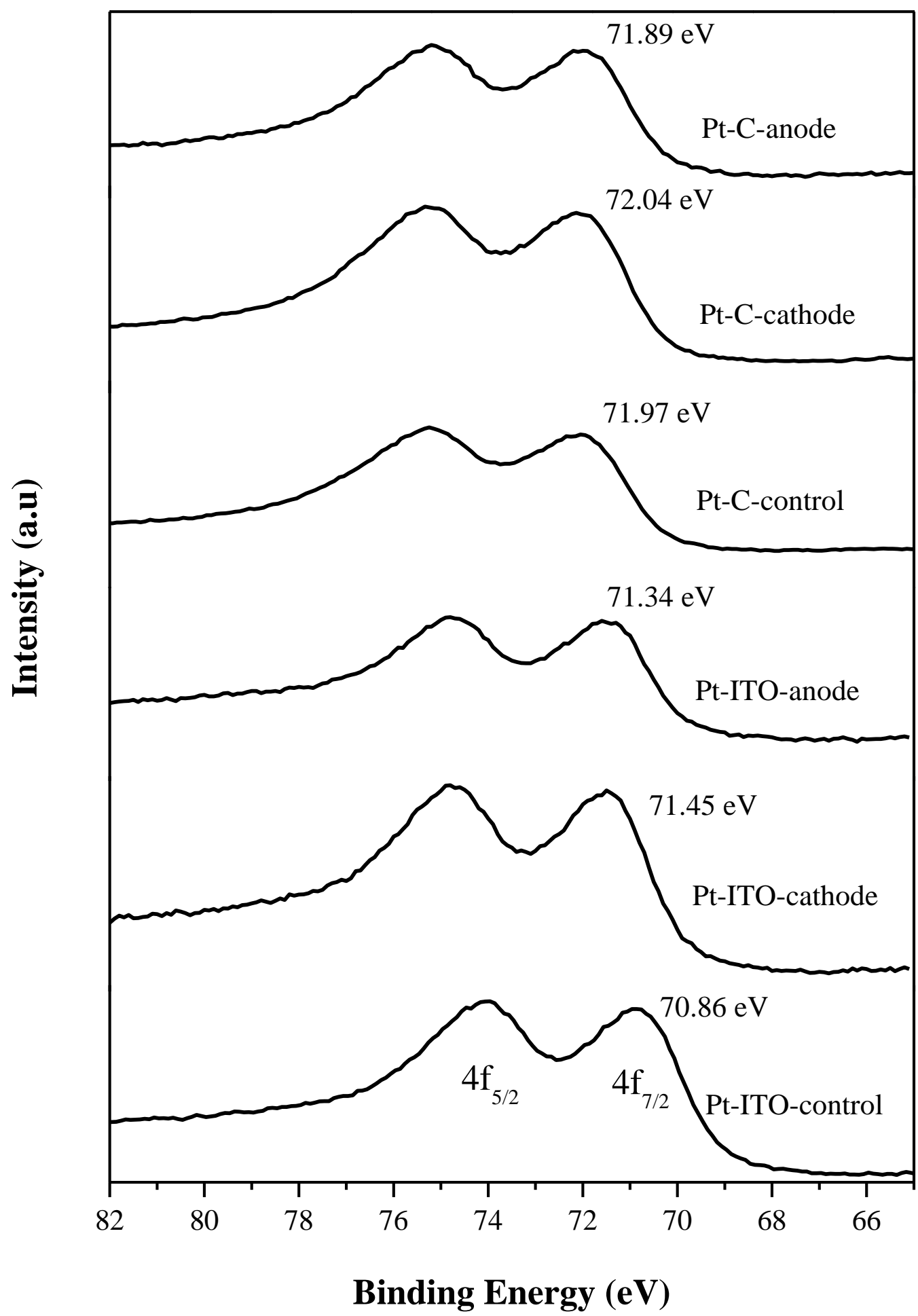

Figure 3. Pt $4 \mathrm{f}$ region of the XPS spectra of Pt/ITO and Pt/C electrodes before and after fuel cell operation. Anode and cathode in the labels refer to the electrodes being tested at the anode or cathode of the PEFC. 
Figure 3 shows the Pt 4f region of the XPS spectra. The Pt/ITO control showed the peaks for Pt $4 \mathrm{f}_{5 / 2}$ and $4 \mathrm{f}_{7 / 2}$ at 74.02 and $70.86 \mathrm{eV}$, respectively, which is in good agreement with previous work (Chen et al., 2010). The binding energies for $\mathrm{Pt}_{4} \mathrm{f}_{7 / 2}$ in $\mathrm{Pt} / \mathrm{ITO}$ electrodes after operation at the anode and cathode were $0.48 \mathrm{eV}$ and $0.59 \mathrm{eV}$ larger than in the control, respectively. The binding energies for $\mathrm{Pt} 4 \mathrm{f}_{5 / 2}$ and $4 \mathrm{f}_{7 / 2}$ in the $\mathrm{Pt} / \mathrm{C}$ control sample were 75.24 and $71.97 \mathrm{eV}$, respectively. The corresponding values for $\left(\mathrm{Pt}_{4} \mathrm{f}_{7 / 2}\right)$ after being operated at the anode and cathode were nearly unchanged at $71.89 \mathrm{eV}$ and $72.04 \mathrm{eV}$, respectively. The XPS measurements were obtained under electrically unbiased conditions and therefore reflect the structural parameters (electronic structure) of the catalysts. Compared with the control group, the higher Pt binding energy of the Pt/ITO suggests that it will be less effective as an electrocatalyst (Pt oxides will be formed more easily). The increase in the Pt binding energy in Pt/ITO after operation at the anode or cathode of the PEFC is consistent with the deterioration in performance seen after such operation.

Figure S9 shows the oxygen 1s (O-1s) region of the XPS spectra for all the catalysts tested. The peaks were deconvoluted and quantified using CASA software where the baseline was removed using a Shirley background function. The peaks were taken as GL(30) [Gaussian to Lorentzian with Gaussian -30\%] ; we calculated the percentage area coverage in each peak. The O-1s peak deconvolution results are provided in a tabulated form in the Supplementary Information in Table S2. Since oxygen is present as an integral part of the ITO structure, the O-1s spectra for Pt/ITO catalysts contains a substantial amount of information about the ITO surface. However, in the case of $\mathrm{Pt} / \mathrm{C}$, the O-1s spectra arises largely from the presence of Nafion ${ }^{\circledR}$ (the ether groups in the perfluorinated polymer) and perhaps due to the presence of $\mathrm{O}$ - in the sulfonic acid group chains in Nafion ${ }^{\circledR}$ or surface oxides/hydroxides on the Pt and carbon. Only a very small amount of $\mathrm{O}$ was found in the Pt/C catalysts. Peak deconvolution showed the presence of two peaks related to the structural O (oxide) and the hydroxide (See Figure S10 in the ESI). 
The binding energy for O1s in pristine Pt/ITO was $529.9 \mathrm{eV}$. Upon use in the cathode and anode, the $\mathrm{O} 1 \mathrm{~s}$ binding energy increased to 530.76 and $530.69 \mathrm{eV}$, respectively. Peak deconvolution of the O1s peaks was performed by assuming the presence of three overlapping peaks (see Figure 4): 1) peak 1 at $529.9 \mathrm{eV}$, resultant from the oxide in ITO; 2) peak 2 at $530.56 \mathrm{eV}$, associated with the presence of hydroxide groups in the catalysts surface; and 3) peak 3 at $533.79 \mathrm{eV}$, related to the presence of oxygen vacancies in the oxide (Wang et al., 2015). We estimated (with an error limit of $\pm 5 \%$ ) that the oxygen vacancies were $7.5 \%, 16.3 \%$ and $21.6 \%$, for the control, cathode-tested and anode-tested electrocatalysts, respectively. The significant change in oxygen vacancy concentration provided additional confirmation of significant structural change in Pt/ITO upon evaluation in an operating PEFC.

The above assignment of the O-1s XPS peaks was accomplished by using the following correlation. In our work, the ITO was calcined at $820^{\circ} \mathrm{C}$ (i.e. $1093 \mathrm{~K}$ ) for 2.5 hours. Therefore the possibility of a growth of amorphous ITO phase could be ruled out and the ITO is crystalline in nature (C. Nunes de Carvalho, 2000). In prior literature, the O-1s peak at $533.7 \mathrm{eV}$ was assigned to oxides present in the adventitious carbonaceous materials or to $\mathrm{O}$ within the sulfonic acid or to C-O within the ether in the Nafion ${ }^{\circledR}$ chain (Kakuta et al., 1985; Kim et al., 1999; Susac et al., 2001; Nasef and Saidi, 2006; Chen et al., 2007). This assignment perfectly fits the O-1s peak in $\mathrm{Pt}-\mathrm{C}$ and but not the O-1s peak in Pt/ITO. Initially the Nafion ${ }^{\circledR}$ concentration in Pt-ITO is much lower compared to Pt-C. Upon probing (normalized baseline) the O-1s plot of each of them (Figure S13), we find that the O-1s intensity of the Pt-ITO samples was almost double of that of the O-1s feature in Pt-C. O-1s $(533.79 \mathrm{eV})$ representing the $\mathrm{O}-\mathrm{C}$ of $\mathrm{Nafion}^{\circledR}$ would not fit as it possesses a higher binding energy $(534.5 \mathrm{eV})$, and there is a lower peak at $531 \mathrm{eV}$. Intensity-wise it would not be even half of the resultant O-1s of the Pt-ITO. So the $533.79 \mathrm{eV}$ peak does not represent the $\mathrm{O}$ of the organic framework of Nafion ${ }^{\circledR}$. The Yusefi Group (Saáedi et al., 2016) in their study for alkali-metal-doped $\mathrm{ZnO}$ assigned the $\mathrm{O}$-vacancy peak at $533.25 \mathrm{eV}$. Xie et al (Lei et al., 2014) in their work on $\operatorname{In}_{2} \mathrm{O}_{3}$ clearly showed the O-vacancy peaks to be at $531.5 \mathrm{eV}$. The 
Ehrenberg group (Liu et al., 2010) in their study for the O-vacancies via in situ thermal XPS clearly showed the growth of the O-vacancies at $\sim 532 \mathrm{eV}$. Usually the surface coverage for the -OH group in the ITO would be around 5 monolayers, whereas the concentration of O-vacancies will result from either dehydration from the surface, or as a consequence of maintaining electroneutrality in the In-O lattice after Sn doping. Also, usually the O-vacancies usually arise subsequent to the O-1s representing the $-\mathrm{OH}$ group (Bermudez et al., 2006; Brumbach et al., 2007). Thereby we can assign the $533.79 \mathrm{eV}$ peak to that of the oxygen near the O-vacancies.

Figure S11 shows the indium 3d (In 3d) peak for the three Pt/ITO samples. There was a slight shift in the binding energy between the control sample and the tested samples. Figure 5 shows the results for the deconvolution of the In $3 \mathrm{~d}_{5 / 2}$ peaks. The first peak, peak 1 at $445.6 \mathrm{eV}$ corresponds to the indium peak corresponding to the ITO structure(In-O, structural O) whereas the second peak, peak 2 at $446.6 \mathrm{eV}$ is due to the presence of indium peak corresponding to the indium hydroxide structure (In-OH, structural $\mathrm{OH}$ ) (Wang et al., 2015). These results are in contradiction with earlier results wherein only one peak was reported for a similar catalyst (Zhao et al., 2015). In our study, we could clearly observe the concentration of hydroxides on the surface of ITO increasing after the Pt/ITO catalyst was tested in an operating PEFC. Zhao et al. tested the performance of $\mathrm{Pt} / \mathrm{ITO}$ in RDE experiments under alkaline conditions that were quite different from the conditions in a PEFC MEA. The contradiction between our results most likely arise due to the differences in operating environment.

Figure S12 shows the tin 3d (Sn 3d) region of the XPS spectra of Pt/ITO catalysts. There were two peaks at $486.0 \mathrm{eV}$ and $494.4 \mathrm{eV}$ corresponding to $\mathrm{Sn} 3 \mathrm{~d}_{5 / 2}$ and $\mathrm{Sn} 3 \mathrm{~d}_{3 / 2}$ which is in agreement with previous work (Liu and Mustain, 2013). Figure 6 shows the results for the deconvolution of the $\mathrm{Sn} 3 \mathrm{~d}_{5 / 2}$ peaks. Peak 2 at $486.6 \mathrm{eV}$ corresponds to presence of $\mathrm{Sn}^{4+}$ cations in the ITO, whereas Peak 1 at $486.0 \mathrm{eV}$ is due to the presence of $\mathrm{Sn}^{2+}$ (Liu and Mustain, 2013; Zhao et al., 2015). The formation of the $\mathrm{Sn}^{2+}$ most likely occurred during the Pt deposition process. The surface $\mathrm{Sn}^{4+}$ was 
partially reduced alongside the platinum precursor to yield $\mathrm{Sn}^{2+}$. After the fuel cell performance tests, only $\mathrm{Sn}^{4+}$ cations were detected in the ITO lattice in both cathode and anode, further confirming structural changes in ITO upon exposure to the fuel cell environment.

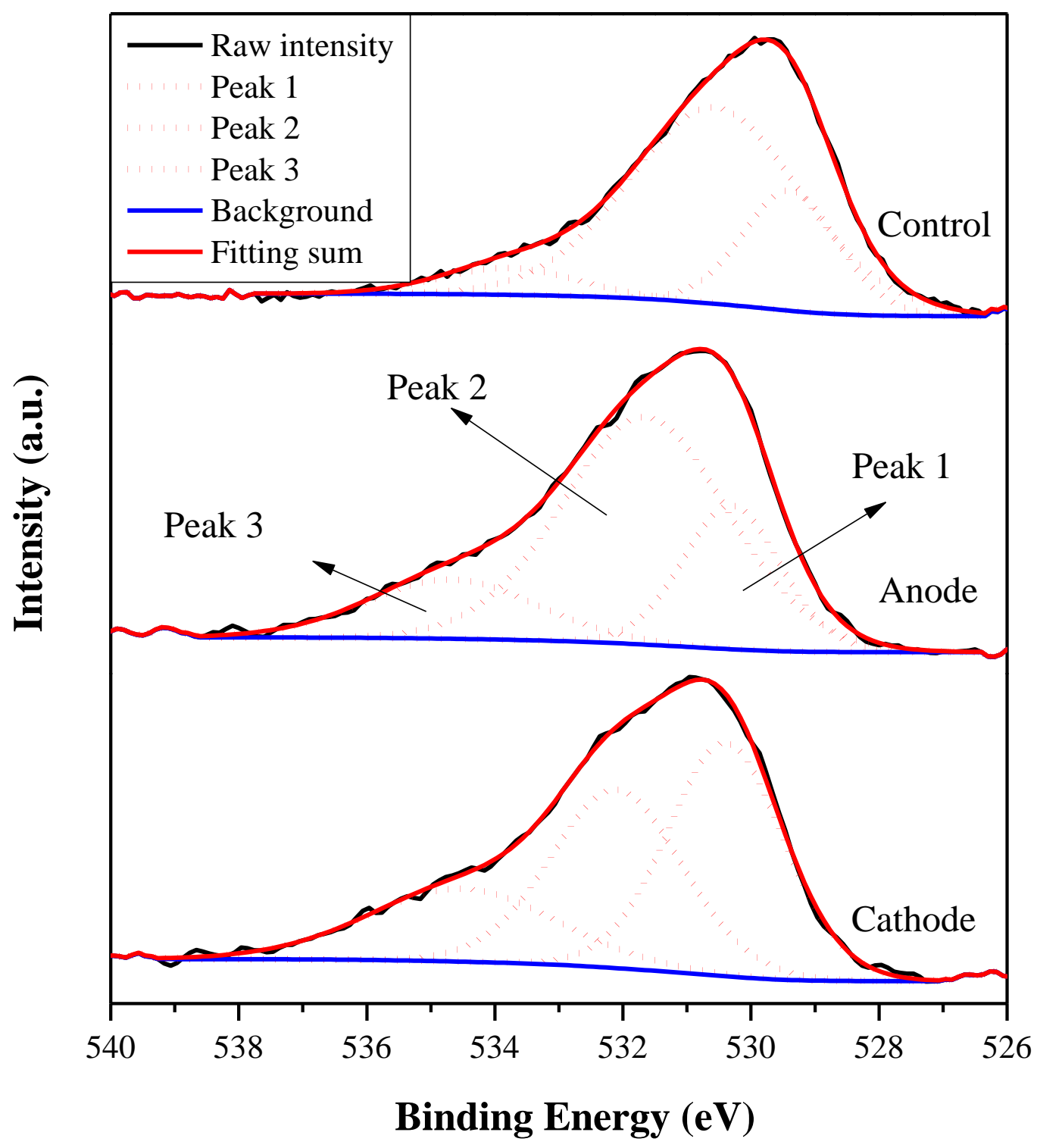

Figure 4. Deconvolution of O-1s peaks for Pt/ITO before and after fuel cell testing. Anode and cathode in the labels refer to electrodes being tested in the anode or cathode of the PEFC. 


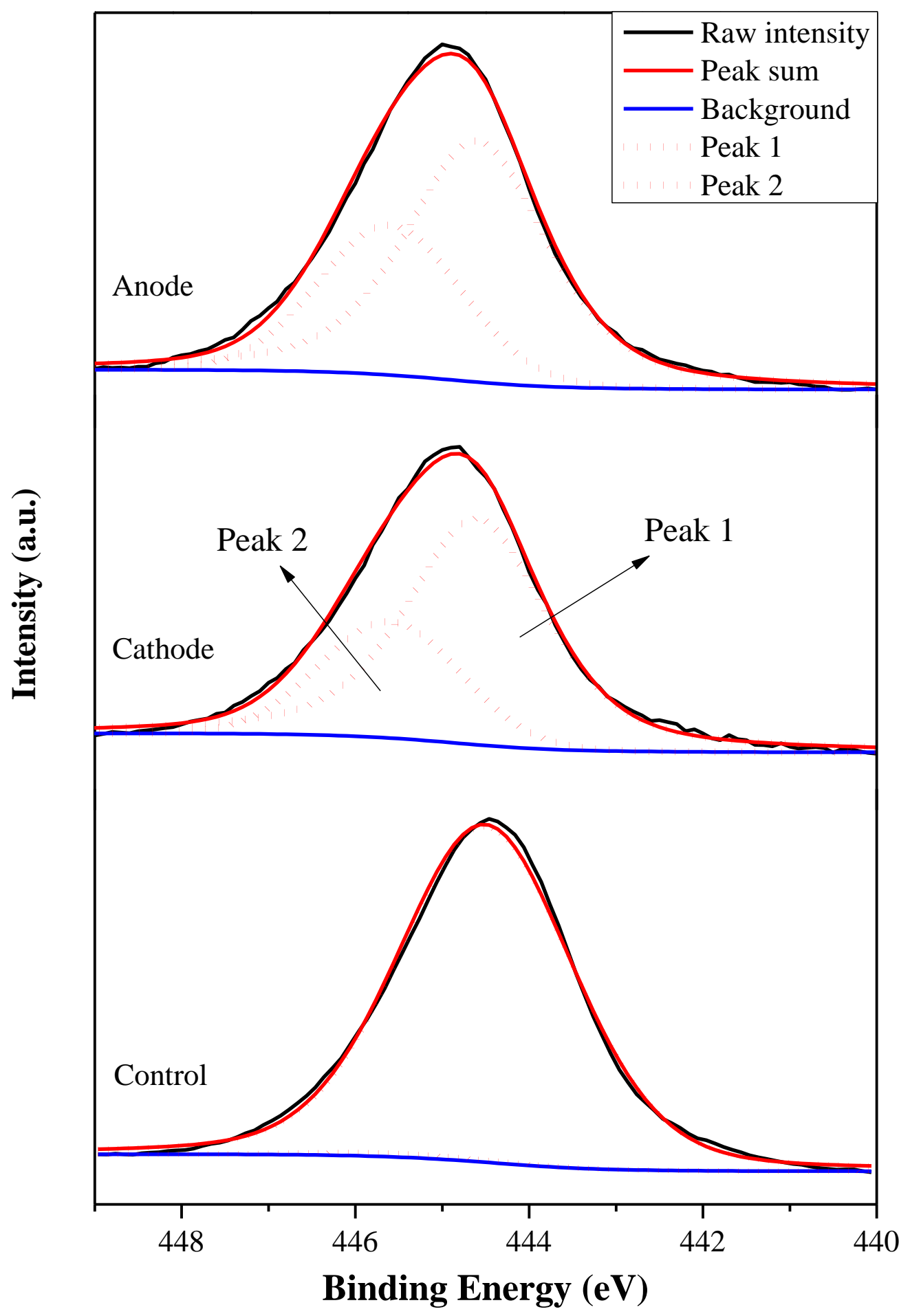

Figure 5. Deconvolution of In-3d $5 / 2$ peaks: a) Pt/ITO control; b) Pt/ITO used in the cathode; and c) Pt/ITO used in the anode 


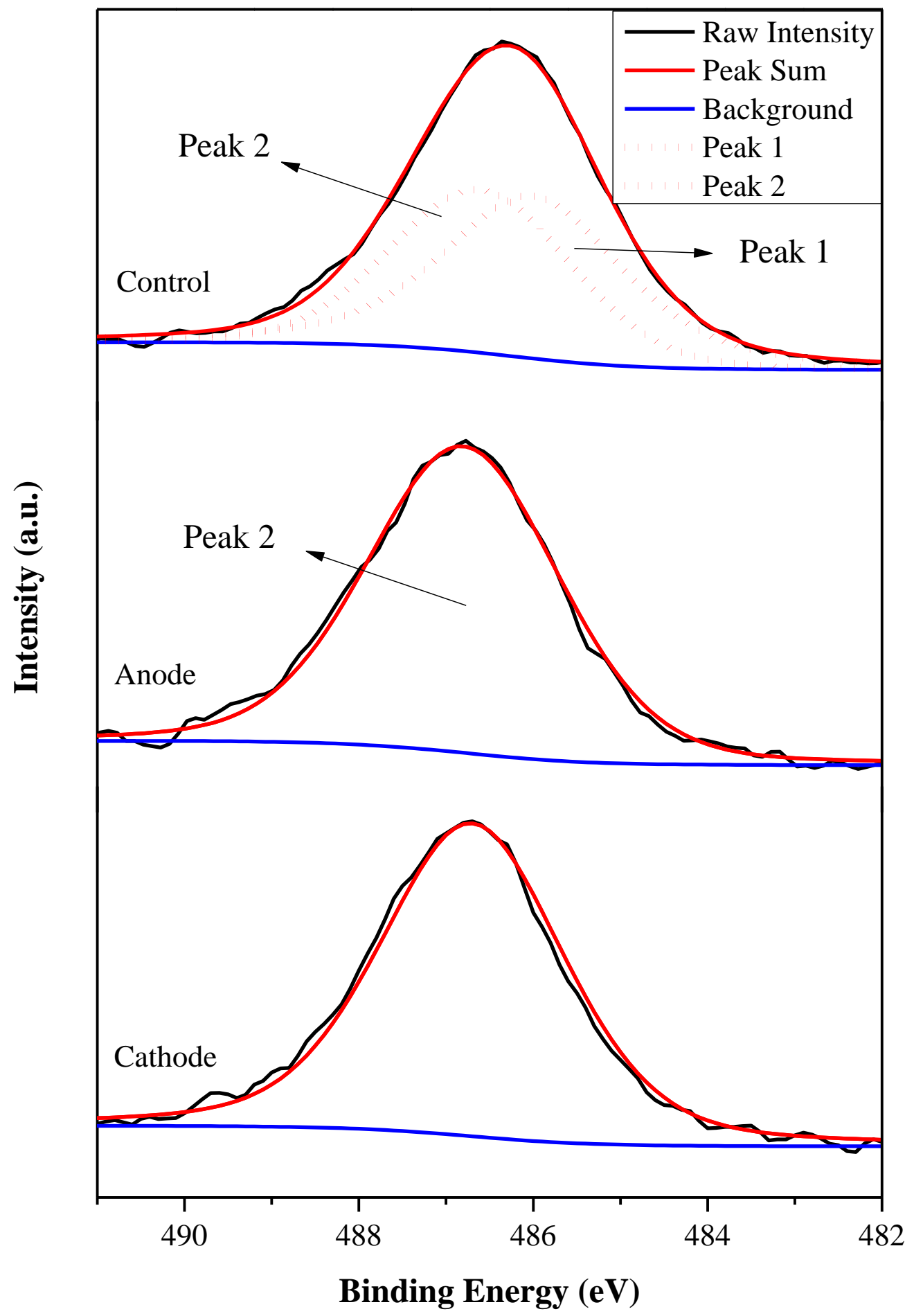

Figure 6. Deconvolution of $\mathrm{Sn} 3 \mathrm{~d}_{5 / 2}$ peaks: a) Pt/ITO control; b) Pt/ITO used in the cathode; and c) Pt/ITO used in the anode 
After detailed analysis of the Pt 4f, O 1s, In 3d and Sn 3d spectra of Pt/ITO, we can arrive at a degradation mechanism for Pt/ITO during fuel cell operation. The degradation of ITO was mainly attributed to the structural changes in $\operatorname{In}_{2} \mathrm{O}_{3}$. From those data, the degradation mechanism for the support can be proposed as below. The surface hydroxide revealed in the XPS studies arise from hydroxylation of the disrupted ITO lattice described in Figure 7 and incomplete hydrolysis of the oxides on the ITO surface:

$$
\begin{gathered}
\mathrm{In}_{2} \mathrm{O}_{3}+3 \mathrm{H}_{2} \mathrm{O} \longrightarrow 2 \mathrm{In}(\mathrm{OH})_{3} \\
\left(\mathrm{In}_{2} \mathrm{O}_{3}+\mathrm{H}_{2} \mathrm{O} \longrightarrow 2 \mathrm{InOOH} ; \mathrm{InOOH}+\mathrm{H}_{2} \mathrm{O} \longrightarrow \operatorname{In}(\mathrm{OH})_{3}\right)
\end{gathered}
$$

The indium hydroxide layer thus generated increases the resistance in the electrodes, and, furthermore can be converted to $\operatorname{In}^{3+}$ in strongly acid conditions. Some of the hydroxylated species may remain adsorbed on the ITO surface and lead to the formation of a passivating layer that increases the resistance of the electrocatalyst layer during operation in an MEA (Donley et al., 2002; Brumbach et al., 2007). It is also possible that the $\mathrm{In}^{3+}$ enters the electrolyte membrane and further enhances resistance by exchanging with protons. Moreover, the $\mathrm{In}^{3+}$ can also exchange with the protons in the ionomer in the electrode, lowering catalytic activity (evidenced by lower ECSA) and further enhancing ohmic losses. So, we believe that the formation of indium hydroxide (and the consequent events described above) is the primary reason for the poor performance of the Pt/ITO electrodes in the MEA. Below is a schematic of the postulated ITO degradation mechanism. 


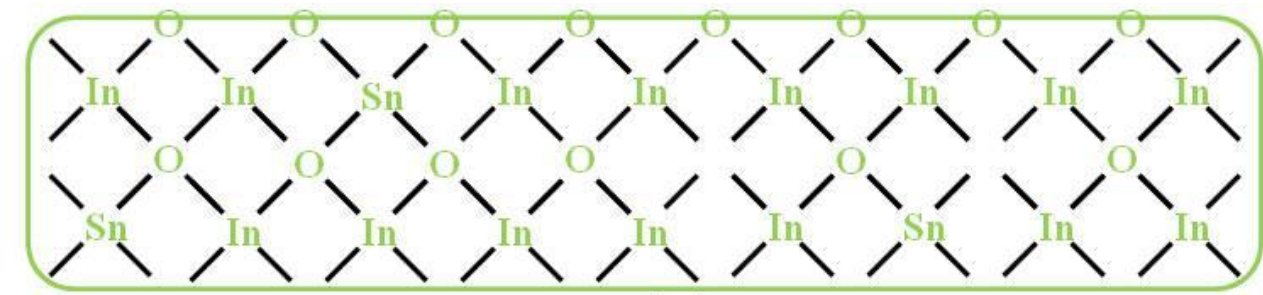

Pristine ITO

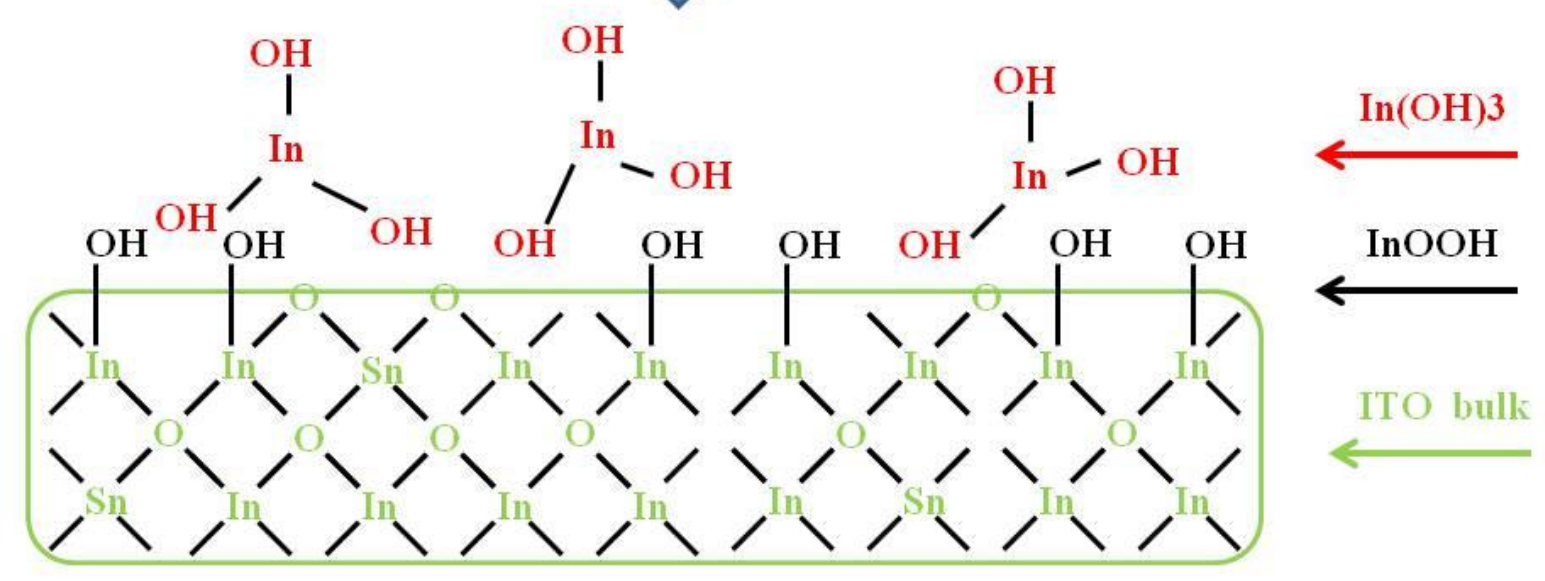

\section{ITO after fuel cell operation}

Figure 7. A schematic view of ITO surface composition after fuel cell operation.

\section{Conclusions}

We have investigated performance and stability of Pt/ITO during operation in a PEFC MEA. ITO was synthesized using the co-precipitation method, and Pt was attached onto the support by colloidal deposition followed by reduction with formaldehyde. MEAs were prepared using $\mathrm{Pt} / \mathrm{ITO}$ at either the anode or cathode, with Pt/C used at the other electrode. An all-Pt/C MEA was also prepared and evaluated to provide a benchmark. Fuel cell polarization curves revealed a very modest performing Pt/ITO catalyst, with poor stability. For an MEA with Pt/ITO at the cathode and $\mathrm{Pt} / \mathrm{C}$ in the anode, under $\mathrm{H}_{2} / \mathrm{O}_{2}$ operation, the current density at $0.55 \mathrm{~V}$ was $90 \mathrm{~mA} / \mathrm{cm}^{2}$, and the maximum current density was only $150-160 \mathrm{~mA} / \mathrm{cm}^{2}$. Under similar experimental conditions, a limiting current density of $3900 \mathrm{~mA} / \mathrm{cm}^{2}$ wasobtained using the 
benchmark MEA. The high cell resistance (larger than $400 \mathrm{mOhm}-\mathrm{cm}^{2}$ ) observed was the principal reason for the low MEA performance when Pt/ITO was employed at either electrode. However, low ECSA and poorer activity of Pt were additional reasons identified. We were able to confirm significant performance degradation during the course of operation even over the short period of a few hours.

XPS was employed to investigate the degradation of the Pt/ITO catalysts in the electrodes and to unearth the degradation mechanism. Our studies clearly show structural changes in the indium oxide component, with the formation of surface hydroxides being quite evident. This hydroxide layer has poor conductivity (in contrast to ITO) which raises the electrode resistance and negatively impacts MEA performance. Indium in the hydroxide layer can dissolve under strongly acidic conditions, leading to $\mathrm{In}^{3+}$ ion infiltration into the membrane (and into the ionomer in the electrode). These events will further increase cell resistance and will lower ECSA and catalytic activity (both of which were observed in our experiments).

\section{Acknowledgements}

V.R acknowledges the US Department of Energy (Energy Efficiency and Renewable Energy Office) for funding this work, through grant DE-EE-0000461. 


\section{References}

Antolini, E., Gonzalez, E.R., 2009. Ceramic materials as supports for low-temperature fuel cell catalysts. Solid State Ionics 180, 746-763.

Avasarala, B., Haldar, P., 2010. Electrochemical oxidation behavior of titanium nitride based electrocatalysts under PEM fuel cell conditions. Electrochimica Acta 55, 9024-9034.

Bellingham, J.R., Mackenzie, A.P., Phillips, W.A., 1991. Precise measurements of oxygen content: oxygen vacancies in transparent conducting indium oxide films. Applied Physics Letters 58, 2506-2508.

Bermudez, V.M., Berry, A.D., Kim, H., Pique, A., 2006. Functionalization of indium tin oxide. Langmuir 22, 11113-11125.

Borup, R., Meyers, J., Pivovar, B., Kim, Y.S., Mukundan, R., Garland, N., Myers, D., Wilson, M., Garzon, F., Wood, D., Zelenay, P., More, K., Stroh, K., Zawodzinski, T., Boncella, J., McGrath, J.E., Inaba, M., Miyatake, K., Hori, M., Ota, K., Ogumi, Z., Miyata, S., Nishikata, A., Siroma, Z., Uchimoto, Y., Yasuda, K., Kimijima, K., Iwashita, N., 2007. Scientific aspects of polymer electrolyte fuel cell durability and degradation. Chem Rev 107, 3904-3951.

Brumbach, M., Veneman, P.A., Marrikar, F.S., Schulmeyer, T., Simmonds, A., Xia, W., Lee, P., Armstrong, N.R., 2007. Surface composition and electrical and electrochemical properties of freshly deposited and acid-etched indium tin oxide electrodes. Langmuir 23, 11089-11099.

Chen, C., Levitin, G., Hess, D.W., Fuller, T.F., 2007. XPS investigation of Nafion® membrane degradation. Journal of Power Sources 169, 288-295.

Chen, G., Bare, S.R., Mallouk, T.E., 2002. Development of Supported Bifunctional Electrocatalysts for Unitized Regenerative Fuel Cells. Journal of The Electrochemical Society 149, A1092-A1099.

Chen, L., Tan, W., Zhang, J., Zhou, X., Zhang, X., Lin, Y., 2010. Fabrication of high performance Pt counter electrodes on conductive plastic substrate for flexible dye-sensitized solar cells. Electrochimica Acta 55, 3721-3726.

Chhina, H., Campbell, S., Kesler, O., 2006. An oxidation-resistant indium tin oxide catalyst 
support for proton exchange membrane fuel cells. Journal of Power Sources 161, 893-900.

Chhina, H., Campbell, S., Kesler, O., 2007. Thermal and electrochemical stability of tungsten carbide catalyst supports. Journal of Power Sources 164, 431-440.

Corradini, A., Marinangeli, A.M., Mastragostino, M., 1990. Ito as counter-electrode in a polymer based electrochromic device. Electrochimica Acta 35, 1757-1760.

Cui, X., Shi, J., Chen, H., Zhang, L., Guo, L., Gao, J., Li, J., 2008. Platinum/Mesoporous WO3 as a Carbon-Free Electrocatalyst with Enhanced Electrochemical Activity for Methanol Oxidation. The Journal of Physical Chemistry B 112, 12024-12031.

Darling, R.M., Meyers, J.P., 2003. Kinetic Model of Platinum Dissolution in PEMFCs. Journal of The Electrochemical Society 150, A1523.

Donley, C., Dunphy, D., Paine, D., Carter, C., Nebesny, K., Lee, P., Alloway, D., Armstrong, N.R., 2002. Characterization of Indium-Tin Oxide Interfaces Using X-ray Photoelectron Spectroscopy and Redox Processes of a Chemisorbed Probe Molecule: Effect of Surface Pretreatment Conditions. Langmuir 18, 450-457.

Exarhos, G.J., Zhou, X.-D., 2007. Discovery-based design of transparent conducting oxide films. Thin Solid Films 515, 7025-7052.

Ferreira, P.J., la O’, G.J., Shao-Horn, Y., Morgan, D., Makharia, R., Kocha, S., Gasteiger, H.A., 2005. Instability of Pt / C Electrocatalysts in Proton Exchange Membrane Fuel Cells: A Mechanistic Investigation. Journal of The Electrochemical Society 152, A2256-A2271.

Granqvist, C.G., 2007. Transparent conductors as solar energy materials: A panoramic review. Solar Energy Materials and Solar Cells 91, 1529-1598.

Haas, O.E., Briskeby, S.T., Kongstein, O.E., Tsypkin, M., Tunold, R., Børresen, B.T., 2008. Synthesis and Characterisation of RuxTix-1O2 as a Catalyst Support for Polymer Electrolyte Fuel Cell. Journal of New Materials for Electrochemical Systems 11, 9-14.

Hagemeyer, A., Hogan, Z., Schlichter, M., Smaka, B., Streukens, G., Turner, H., Volpe Jr, A., Weinberg, H., Yaccato, K., 2007. High surface area tin oxide. Applied Catalysis A: General 317, $139-148$. 
Ho, V.T.T., Pan, C.-J., Rick, J., Su, W.-N., Hwang, B.-J., 2011. Nanostructured Ti0.7Mo0.3O2 Support Enhances Electron Transfer to Pt: High-Performance Catalyst for Oxygen Reduction Reaction. Journal of the American Chemical Society 133, 11716-11724.

Huang, S.-Y., Ganesan, P., Popov, B.N., 2010. Electrocatalytic activity and stability of niobium-doped titanium oxide supported platinum catalyst for polymer electrolyte membrane fuel cells. Applied Catalysis B: Environmental 96, 224-231.

Kakuta, N., White, J.M., Campion, A., Bard, A.J., Fox, M.A., Webber, S.E., 1985. Surface analysis of semiconductor-incorporated polymer systems. 1. Nafion and cadmium sulfide-Nafion. The Journal of Physical Chemistry 89, 48-52.

Kangasniemi, K.H., Condit, D.A., Jarvi, T.D., 2004. Characterization of Vulcan Electrochemically Oxidized under Simulated PEM Fuel Cell Conditions. Journal of The Electrochemical Society 151, E125-E132.

Kazunari, O., Tianchun, Y., Yoshinobu, A., 1994. Deposition of thin indium oxide film and its application to selective epitaxy for in situ processing. Thin Solid Films 246, 58-64.

Kim, J.S., Ho, P.K.H., Thomas, D.S., Friend, R.H., Cacialli, F., Bao, G.-W., Li, S.F.Y., 1999. $<$ X-ray photoelectron spectroscopy of surface-treated indium-tin oxide thin films.pdf $>$. Chemical Physics Letters 315, 307-312.

Kinoshita, K., Bett, J.A.S., 1973. Potentiodynamic analysis of surface oxides on carbon blacks. Carbon 11, 403-411.

Kohnke, E.E., 1962. Electrical and optical properties of natural stannic oxide crystals. Journal of Physics and Chemistry of Solids 23, 1557-1562.

Kumar, A., Ramani, V., 2014. Strong Metal-Support Interactions Enhance the Activity and Durability of Platinum Supported on Tantalum-Modified Titanium Dioxide Electrocatalysts. ACS Catal 4, 1516-1525.

Kumar, A., Ramani, V.K., 2013. RuO2-SiO2 mixed oxides as corrosion-resistant catalyst supports for polymer electrolyte fuel cells. Applied Catalysis B: Environmental 138-139, 43-50. Lefebvre, M.C., 1999. Characterization of Ionic Conductivity Profiles within Proton Exchange 
Membrane Fuel Cell Gas Diffusion Electrodes by Impedance Spectroscopy. Electrochemical and Solid-State Letters 2, 259.

Lei, F., Sun, Y., Liu, K., Gao, S., Liang, L., Pan, B., Xie, Y., 2014. Oxygen vacancies confined in ultrathin indium oxide porous sheets for promoted visible-light water splitting. J Am Chem Soc 136, 6826-6829.

Liu, H., Liu, Y., Li, Y., Tang, Z., Jiang, H., 2010. Metal-Organic Framework Supported Gold Nanoparticles as a Highly Active Heterogeneous Catalyst for Aerobic Oxidation of Alcohols. The Journal of Physical Chemistry C 114, 13362-13369.

Liu, Y., Kelly, T.G., Chen, J.G., Mustain, W.E., 2013. Metal Carbides as Alternative Electrocatalyst Supports. ACS Catal 3, 1184-1194.

Liu, Y., Murphy, M., Baker, D., Gu, W., Ji, C., Jorne, J., Gasteiger, H.A., 2007. Determination of Electrode Sheet Resistance in Cathode Catalyst Layer by AC Impedance. 11, 473-484.

Liu, Y., Mustain, W.E., 2013. High Stability, High Activity Pt/ITO Oxygen Reduction Electrocatalysts. Journal of the American Chemical Society 135, 530-533.

Liu, Y., Shrestha, S., Mustain, W.E., 2012. Synthesis of Nanosize Tungsten Oxide and Its Evaluation as an Electrocatalyst Support for Oxygen Reduction in Acid Media. ACS Catal 2, 456-463.

Lo, C.-P., Ramani, V., 2012. SiO2-RuO2: A Stable Electrocatalyst Support. ACS Applied Materials \& Interfaces 4, 6109-6116.

Lo, C.-P., Wang, G., Kumar, A., Ramani, V., 2013. TiO2-RuO2 electrocatalyst supports exhibit exceptional electrochemical stability. Applied Catalysis B: Environmental 140-141, 133-140.

Maass, S., Finsterwalder, F., Frank, G., Hartmann, R., Merten, C., 2008. Carbon support oxidation in PEM fuel cell cathodes. Journal of Power Sources 176, 444-451.

Mahlon S. Wilson, F.H.G., Kurt E. Sickafus, and Shimshon Gottesfeld, 1993. Surface Area Loss of Supported Platinum in Polymer Electrolyte Fuel Cells. J. Electrochem. Soc. 140, 6.

Makharia, R., Mathias, M.F., Baker, D.R., 2005. Measurement of Catalyst Layer Electrolyte Resistance in PEFCs Using Electrochemical Impedance Spectroscopy. Journal of The 
Electrochemical Society 152, A970.

Meyers, J.P., Darling, R.M., 2006. Model of Carbon Corrosion in PEM Fuel Cells. Journal of The Electrochemical Society 153, A1432.

Nasef, M.M., Saidi, H., 2006. Surface studies of radiation grafted sulfonic acid membranes: XPS and SEM analysis. Applied Surface Science 252, 3073-3084.

Parrondo, J., Han, T., Niangar, E., Wang, C., Dale, N., Adjemian, K., Ramani, V., 2014. Platinum supported on titanium-ruthenium oxide is a remarkably stable electrocatayst for hydrogen fuel cell vehicles. Proceedings of the National Academy of Sciences of the United States of America $111,45-50$.

Patterson, T.W., Darling, R.M., 2006. Damage to the Cathode Catalyst of a PEM Fuel Cell Caused by Localized Fuel Starvation. Electrochemical and Solid-State Letters 9, A183.

Pourbaix, M., 1974. Atlas of Electrochemical Equilibria in Aqueous Solutions, 2nd ed. National Association of Corrosion, Houston, Texas.

Rajeswari, J., Viswanathan, B., Varadarajan, T.K., 2007. Tungsten trioxide nanorods as supports for platinum in methanol oxidation. Materials Chemistry and Physics 106, 168-174.

Reiser, C.A., Bregoli, L., Patterson, T.W., Yi, J.S., Yang, J.D., Perry, M.L., Jarvi, T.D., 2005. A Reverse-Current Decay Mechanism for Fuel Cells. Electrochemical and Solid-State Letters 8, A273-A276.

Roen, L.M., Paik, C.H., Jarvi, T.D., 2004. Electrocatalytic Corrosion of Carbon Support in PEMFC Cathodes. Electrochemical and Solid-State Letters 7, A19-A22.

Saadeddin, I., Pecquenard, B., Manaud, J.P., Decourt, R., Labrugère, C., Buffeteau, T., Campet, G., 2007. Synthesis and characterization of single- and co-doped $\mathrm{SnO} 2$ thin films for optoelectronic applications. Applied Surface Science 253, 5240-5249.

Saáedi, A., Yousefi, R., Jamali-Sheini, F., Zak, A.K., Cheraghizade, M., Mahmoudian, M.R., Baghchesara, M.A., Dezaki, A.S., 2016. XPS studies and photocurrent applications of alkali-metals-doped $\mathrm{ZnO}$ nanoparticles under visible illumination conditions. Physica E: Low-dimensional Systems and Nanostructures 79, 113-118. 
Santos, A.L., Profeti, D., Olivi, P., 2005. Electrooxidation of methanol on Pt microparticles dispersed on $\mathrm{SnO} 2$ thin films. Electrochimica Acta 50, 2615-2621.

Schneider, I.A., von Dahlen, S., 2011. Start-Stop Phenomena in Channel and Land Areas of a Polymer Electrolyte Fuel Cell. Electrochemical and Solid-State Letters 14, B30.

Seger, B., Kongkanand, A., Vinodgopal, K., Kamat, P.V., 2008. Platinum dispersed on silica nanoparticle as electrocatalyst for PEM fuel cell. Journal of Electroanalytical Chemistry 621, 198-204.

Shanmugam, S., Jacob, D.S., Gedanken, A., 2005. Solid State Synthesis of Tungsten Carbide Nanorods and Nanoplatelets by a Single-Step Pyrolysis. The Journal of Physical Chemistry B 109, 19056-19059.

Shao, Y., Yin, G., Gao, Y., 2007. Understanding and approaches for the durability issues of Pt-based catalysts for PEM fuel cell. Journal of Power Sources 171, 558-566.

Sharma, S., Pollet, B.G., 2012. Support materials for PEMFC and DMFC electrocatalysts-A review. Journal of Power Sources 208, 96-119.

Shen, Q., Hou, M., Liang, D., Zhou, Z., Li, X., Shao, Z., Yi, B., 2009. Study on the processes of start-up and shutdown in proton exchange membrane fuel cells. Journal of Power Sources 189, 1114-1119.

Song, J.O., Jun-Seok, H., Seong, T.-Y., 2010. Ohmic-Contact Technology for GaN-Based Light-Emitting Diodes: Role of P-Type Contact. IEEE Transactions on Electron Devices 57, $42-59$.

Susac, D., Kono, M., Wong, K.C., Mitchell, K.A.R., 2001. XPS study of interfaces in a two-layer light-emitting diode made from PPV and Nafion with ionically exchanged Ru(bpy)32+. Applied Surface Science 174, 43-50.

Takeuchi, N., Fuller, T.F., 2008. Modeling and Investigation of Design Factors and Their Impact on Carbon Corrosion of PEMFC Electrodes. Journal of The Electrochemical Society 155, B770. Tang, H., Qi, Z., Ramani, M., Elter, J.F., 2006. PEM fuel cell cathode carbon corrosion due to the formation of air/fuel boundary at the anode. Journal of Power Sources 158, 1306-1312. 
Thanh Ho, V.T., Pillai, K.C., Chou, H.-L., Pan, C.-J., Rick, J., Su, W.-N., Hwang, B.-J., Lee, J.-F., Sheu, H.-S., Chuang, W.-T., 2011. Robust non-carbon Ti0.7Ru0.3O2 support with co-catalytic functionality for Pt: enhances catalytic activity and durability for fuel cells. Energy \& Environmental Science 4, 4194-4200.

Wang, G., Niangar, E., Huang, K., Atienza, D., Kumar, A., Dale, N., Oshihara, K., Ramani, V.K., 2015. Indium Tin Oxide as Catalyst Support for PEM Fuel Cell: RDE and MEA Performance. ECS Transactions 69, 1179-1205.

Wang, X., Kumar, R., Myers, D.J., 2006. Effect of Voltage on Platinum Dissolution. Electrochemical and Solid-State Letters 9, A225.

Wang, Y.J., Wilkinson, D.P., Zhang, J., 2011. Noncarbon support materials for polymer electrolyte membrane fuel cell electrocatalysts. Chem Rev 111, 7625-7651.

Yu, X., Ye, S., 2007. Recent advances in activity and durability enhancement of Pt/C catalytic cathode in PEMFC. Journal of Power Sources 172, 145-154.

Zhang, J., Sasaki, K., Sutter, E., Adzic, R.R., 2007. Stabilization of Platinum Oxygen-Reduction Electrocatalysts Using Gold Clusters. Science 315, 220-222.

Zhao, S., Wangstrom, A.E., Liu, Y., Rigdon, W.A., Mustain, W.E., 2015. Stability and Activity of Pt/ITO Electrocatalyst for Oxygen Reduction Reaction in Alkaline Media. Electrochimica Acta $157,175-182$.

Zhu, X.-B., Zhang, H.-M., Liang, Y.-M., Zhang, Y., Yi, B.-L., 2006. A Novel PTFE-Reinforced Multilayer Self-Humidifying Composite Membrane for PEM Fuel Cells. Electrochemical and Solid-State Letters 9, A49-A52. 